\title{
Incidence of phosphate solubilising fungal population in soils of Barbara forest of Odisha, India
}

\begin{abstract}
The present study deals with the isolation of soil fungi from Barbara forest of Odisha and screening for their phosphate solubilising potential under submerged culture in presence of TCP and rock phosphate. The soil samples collected from 20 different sites showed $\mathrm{pH}$ ranged from 4.8-7.6. Analysis of soluble $\mathrm{P}$ content was ranged from $26.88-277.76 \mathrm{~kg} / \mathrm{ha}$. Evaluation of fungal population in soils of different sites exhibited the highest fungal count in site one $(2.92 \pm 2.23 \mathrm{cfu} / \mathrm{g})$ followed by site $10(2.7 \pm 0 \mathrm{cfu} / \mathrm{g})$. The maximum PSF was found in Site $2(0.625 \pm 0.25 \mathrm{cfu} / \mathrm{g})$ and $10(0.76 \pm 0.7 \mathrm{cfu} / \mathrm{g})$ soils Among all fungal population of all sites of soils studied, six fungi were found as phosphate solubilisers having 1.28-1.5colonization index. Penicillium sp. showed higher TCP solubilisation potential $(36.7 \pm 2.31 \%)$ whereas Aspergillus sp. had the capacity to solubilise Rock phosphate besides TCP also. Outcome of present study clearly indicate the presence of fungi with a good potential of mineral solubilisation in these soils. Further, experimental evidence is required to explore the possibility of these fungi for field application.
\end{abstract}

Keywords: fungi, forest, phosphate solubilisation, TCP, rock phosphate
Volume 5 Issue 3 - 2016

\author{
Hruda Ranjan Sahoo, Nibha Gupta \\ Division of Plant Pathology and Microbiology, Regional Plant \\ Resource Centre, India
}

\begin{abstract}
Correspondence: Nibha Gupta, Division of Plant Pathology and Microbiology, Regional Plant Resource Centre, Bhubaneswar-751015, Odisha, India, Tel 0674-255-792-5(O), Email nguc2003@yahoo.co.in
\end{abstract}

Received: September 22, 2015 | Published: December 0I, 2016

\section{Introduction}

Microbes play an important role in biogeochemical cycle and helping plants to grow and develop and ultimately enhancing the productivity. ${ }^{1,2}$ Mineral solubilisation is an important phenomenon in this regard which several bacteria and fungi impart due to their secondary metabolism especially organic acid production. ${ }^{3,4}$ Phosphorus is one of the major plant nutrients but approximately 95-99\% is present in unutilised bound form and induces the soil for application of phosphate fertilizer. However the efficiency of chemical fertilizer is still low ranged between $5-10 \%{ }^{5}$ Hence, preliminary criteria for the agronomic management of fertility of soil are to

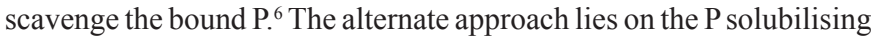
microbes. Several studies have been reported on the occurrence and application of phosphate solubilising microbes from different soil and cultural improvement in crop productivity. ${ }^{7}$ Phosphofungi belong predominantly to the Aspergillus and Penicillium genera, and several other strains have been identified that benefit the nutrient concentrations and yield under both greenhouse and field conditions. ${ }^{8}$ However, the beneficial effect on plants may be influenced by various edaphic and climatic factors and biological interaction. Hence exploration of indigenous microbes should be emphasized in order to obtain suitable and interactive microbial strains. In view to this, the present study was aimed to study indigenous phosphate solubilising microbes especially fungi from forest soil of Odisha.

\section{Materials and methods}

\section{Collection and analysis of soil samples}

Soil samples were collected from 20 different sites of Barbara forest Division, Khurdha district, Odisha during November, 2012 and $\mathrm{pH}$ was measured. Soluble P content in soil was analysed according to Bray and Kurtz method, 1945 for which $2.5 \mathrm{~g}$ soil is taken in $150 \mathrm{ml}$ flask and added with $25 \mathrm{ml}$ of extracting solution (NH4F and conc. $\mathrm{HCl}$ ) under shaking at $180 \mathrm{rpm} .5 \mathrm{ml}$ filtered solution was used for estimation of $\mathrm{P}$ by adding $15 \mathrm{ml}$ of distilled water and $4 \mathrm{ml}$ of reagent(reagent $\mathrm{A}$-ammonium molybdate and antimony potassium tartarate and reagent $\mathrm{B}$-ascorbic acid mixture) and measured at $730 \mathrm{~nm}$ . P content was calculated as per Bray's formula. ${ }^{9}$

\section{Isolation and evaluation of fungi from soil samples}

Diluted $1 \mathrm{~g}$ soil sample (1/100) was plated on Pikovskaya's agar medium and incubated for 10 days in order to separate halo zone forming fungal colonies as well as total CFU of fungi. The positive fungal strains were identified morphologically $y^{10,11}$ and reinoculated in Pikovskaya's medium in order to determine Solubilization Efficiency and Solubilization Index. ${ }^{12,13}$ Quantitative estimation of tri calcium phosphate solubilisation was done by Vanado phosphomolybdate method. ${ }^{14}$ The fungal mycelium was cultured in Pikovskaya's broth medium (added separately with TCP and Rock phosphate) with initial $\mathrm{pH} 7.1$ at $28^{\circ} \mathrm{C}$ for 10 days in dark by adding equal amount of inoculums to each of the flasks. Finally, $\mathrm{P}$ content and $\mathrm{pH}$ was measured in culture filtrate by using vanado phosphomolybdate reagent and measured at $420 \mathrm{~nm}$.

\section{Results and discussion}

Soil samples collected from 20 different sites had a different texture. Most of them are moist or laterite type except soil of site 1that was sandy type. As shown in Table 1, the $\mathrm{pH}$ of most of the soil was ranged in 5.3-7.6 higher than these of laterite soil which were slightly acidic (4.8-4.9). The P content in two sites ( 3 and 4 ) was higher (277.76 and $259.84 \mathrm{~kg} / \mathrm{ha}$ ). The soil for site 17 was quite low as compared to other sites studied. The P content in some soil was low due to most of the $\mathrm{P}$ found as unavailable or fixed form. ${ }^{15}$ It is the reason that most of the tropical soils are P deficient and mostly dependent on chemical fertilisers for plant growth promotion. ${ }^{15,16}$ Total fungal population in site 1 was higher than other soil sites $(2.92 \pm 2.23) \mathrm{cfu} / \mathrm{g}$ followed by site 10 $(2.7 \pm 0) \mathrm{cfu} / \mathrm{g}$ and site 4 and $5(2.62 \pm 0$ and $2.6 \pm 0) \mathrm{cfu} / \mathrm{g}$. Besides other soil samples exhibited moderate no. of fungal colonies (Table 2). In 
comparison to others, soil of sites 8,16 and 20 had very low microbial (fungal) population. The difference may not be due to soil types as both the types moist and laterite have shown varied fungal population except soil of site no.1 that was sandy in texture. Since the soil was collected from forest region, where mixed population of forest trees and orchids observed, the types and edaphic factor may also influence the population of existing micro flora. A good number of phosphate solubilising fungal populationswere observed during this study (Table 2). Soils collected from 2 sites i.e. S2 and S15 exhibited higher \% of occurrence of PSF $59.63 \%$ and $42.80 \%$ respectively. Though soils of site 1 and site 10 had higher CFU, a moderate population of PSF could be isolated from these soils. For screening of PSM, the solubilisation of Calcium phosphate compounds like DCP, TCP or hydroxyapatite generally used. However, present study reveals the occurrence of micro-organisms would be effective for calcareous soil where calcium phosphate is predominant. The alkaline $\mathrm{pH}$ of soil samples used in this study also complement this phenomenon, as acidic soil do fixation with $\mathrm{Fe}$ or $\mathrm{Al}$ ions. ${ }^{15}$

Results revealed no correlation among soil type, \% occurrence, total population and soil properties. The difference may be due to other environmental and edaphic factors. Among all 20 soil samples used for occurrence of PSF, only six type of fungi belonging to Penicillium (2 sp.) and Aspergillus (3 sp.) showed phosphate solubilisation capacity under solid culture conditions. More or less, all had similar Solubilisation efficiency (\%) except for Aspergillussp. 2 had 50\% (Figure 1). Similar pattern of Solubilisation Index was also observed (Figure 2). Phosphate solubilising efficiency of these fungal strains was also evaluated in submerged culture conditions supplemented with TCP and Rock phosphate separately. The $\mathrm{pH}$ of the culture filtrate under TCP addition was declined to 4.04 and 4.72 in case of Aspergillus sp. 3 and Aspergillus sp. 1 respectively (Figure $3)$. However, it is not the indication of good TCP solubilisation as Penicillium sp. 1 had $36.7 \%$ P solubilisation, showed $6.09 \mathrm{pH}$ of the medium. Penicillium sp. 2 also had similar performance. All fungal isolates exhibited Rock phosphate solubilisation too. No significant change in $\mathrm{pH}$ of the medium could be observed except Aspergillus $s p .3$ showed decline in $\mathrm{pH}$ up to 5.76 and could solubilise $31.3 \%$ rock phosphate whereas other have shown poor capacity for solubilising rock phosphate under this culture conditions (Figure 4).

Table I Collection sites and basic characteristics of soils

\begin{tabular}{|c|c|c|c|c|c|}
\hline Site & GPS reading & Soil texture & $\mathrm{pH}\left(\mathrm{H}_{2} \mathrm{O}\right)$ & Bray's $P$ in $\mu g$ & Bray's $P$ in $\mu g(\mathrm{~kg} / \mathrm{ha})$ \\
\hline S1 & $19^{0} 51^{\prime} .038 \mathrm{~N}, 85^{0} 01^{\prime} .042 \mathrm{E}$ & sandy & 7.3 & 42 & 188.16 \\
\hline S2 & $19^{0} 53^{\prime} .038 \mathrm{~N}, 85^{0} 03^{\prime} .214 \mathrm{E}$ & moist & 7 & 32 & 143.36 \\
\hline S3 & $19^{0} 53^{\prime} .379 \mathrm{~N}, 85^{0} 03^{\prime} .189 \mathrm{E}$ & moist & 7.4 & 62 & 277.76 \\
\hline S4 & $19^{0} 53^{\prime} .379 \mathrm{~N}, 85^{0} 03^{\prime} .189 \mathrm{E}$ & moist & 7.4 & 58 & 259.84 \\
\hline S5 & $19^{0} 53^{\prime} .379 \mathrm{~N}, 85^{0} 03^{\prime} .189 \mathrm{E}$ & moist & 7.2 & 35 & 156.8 \\
\hline S6 & $19^{0} 53^{\prime} .370 \mathrm{~N}, 85^{0} 03^{\prime} .166 \mathrm{E}$ & moist & 7.6 & 29 & 129.92 \\
\hline S7 & $19^{0} 53^{\prime} .038 \mathrm{~N}, 85^{0} 03^{\prime} .214 \mathrm{E}$ & moist & 7.1 & 21 & 94.08 \\
\hline S8 & $19^{0} 53^{\prime} .382 \mathrm{~N}, 85^{0} 03^{\prime} .206 \mathrm{E}$ & laterite & 6.9 & 22 & 98.56 \\
\hline S9 & $19^{0} 53^{\prime} .382 \mathrm{~N}, 85^{0} 03^{\prime} .206 \mathrm{E}$ & laterite & 7.3 & 18 & 80.64 \\
\hline S10 & $19^{0} 53^{\prime} .361 \mathrm{~N}, 85^{0} 03^{\prime} .202 \mathrm{E}$ & laterite & 6 & 15 & 67.2 \\
\hline S11 & $19^{0} 53^{\prime} .361 \mathrm{~N}, 85^{0} 03^{\prime} .202 \mathrm{E}$ & laterite & 5.4 & 12 & 53.76 \\
\hline S12 & $19^{0} 53^{\prime} .364 \mathrm{~N}, 85^{0} 03^{\prime} .154 \mathrm{E}$ & laterite & 4.9 & 26 & 116.48 \\
\hline $\mathrm{S} 13$ & $19^{0} 53^{\prime} .364 \mathrm{~N}, 85^{0} 03^{\prime} .154 \mathrm{E}$ & laterite & 4.8 & 27 & 120.96 \\
\hline S14 & $19^{0} 52^{\prime} .197 \mathrm{~N}, 85^{0} 02^{\prime} .180 \mathrm{E}$ & moist & 6.8 & 19 & 85.12 \\
\hline S15 & $19^{0} 52^{\prime} .197 \mathrm{~N}, 85^{0} 02^{\prime} .180 \mathrm{E}$ & moist & 6.5 & 25 & 112 \\
\hline S16 & $19^{0} 52^{\prime} .330 \mathrm{~N}, 85^{0} 01^{\prime} .587 \mathrm{E}$ & moist & 5.9 & 21 & 94.08 \\
\hline S17 & $19^{0} 52^{\prime} .321 \mathrm{~N}, 85^{0} 01^{\prime} .547 \mathrm{E}$ & moist & 6.3 & 6 & 26.88 \\
\hline S18 & $19^{0} 52^{\prime} .325 \mathrm{~N}, 85^{0} 01^{\prime} .460 \mathrm{E}$ & moist & 5.3 & 22 & 98.56 \\
\hline S19 & $19^{0} 52^{\prime} .325 \mathrm{~N}, 85^{0} 01^{\prime} .460 \mathrm{E}$ & moist & 6.8 & 24 & 107.52 \\
\hline S20 & $19^{0} 52^{\prime} .356 \mathrm{~N}, 85^{0} 01^{\prime} .435 \mathrm{E}$ & moist & 6.9 & 15 & 67.2 \\
\hline
\end{tabular}


Table 2 Fungal population and \% Occurrence of PSF in soils of different sites

\begin{tabular}{|c|c|c|c|}
\hline Site no. & Total fungal population in (x104) cfu/g & Phosphate solubilising fungal population (x104) cfu/g & $\%$ Occurrence of PSF \\
\hline $\mathrm{S} 1$ & $2.92 \pm 2.23$ & $0.625 \pm 0.25$ & $21.40 \%$ \\
\hline S2 & $1.61 \pm 1.26$ & $0.96 \pm 1.05$ & $59.63 \%$ \\
\hline $\mathrm{S} 3$ & $0.87 \pm 0$ & $0.09 \pm 0$ & $10.34 \%$ \\
\hline S4 & $2.62 \pm 0$ & $0.08 \pm 0.03$ & $3.05 \%$ \\
\hline S5 & $2.6 \pm 0$ & $0.38 \pm 0.17$ & $14.60 \%$ \\
\hline S6 & $1.02 \pm 0.4$ & $0.08 \pm 0.03$ & $7.84 \%$ \\
\hline S7 & $0.88 \pm 0.88$ & $0.13 \pm 0.09$ & $14.80 \%$ \\
\hline S8 & $0.19 \pm 0.16$ & $0.03 \pm 0$ & $15.70 \%$ \\
\hline S9 & $1.21 \pm 0.83$ & $0.07 \pm 0.05$ & $5.79 \%$ \\
\hline S10 & $2.7 \pm 0$ & $0.76 \pm 0.7$ & $28.15 \%$ \\
\hline S11 & $1.55 \pm 1.62$ & $0.03 \pm 0$ & $1.94 \%$ \\
\hline $\mathrm{S} 12$ & $0.61 \pm 0$ & $0.06 \pm 0.4$ & $9.83 \%$ \\
\hline S13 & $1.21 \pm 1.27$ & $0.02 \pm 0$ & $1.65 \%$ \\
\hline S14 & $1.25 \pm 1.34$ & $0.19 \pm 0.16$ & $15.20 \%$ \\
\hline S15 & $1.075 \pm 1.17$ & $0.46 \pm 0.4$ & $42.80 \%$ \\
\hline S16 & $0.28 \pm 0.17$ & $0.04 \pm 0$ & $14.30 \%$ \\
\hline S17 & $1.3 \pm 1.42$ & $0.02 \pm 0$ & $1.54 \%$ \\
\hline S18 & $1.1 \pm 0$ & $0.125 \pm 0.1$ & $11.40 \%$ \\
\hline S19 & $1.1 \pm 0.45$ & $0.06 \pm 0.05$ & $5.45 \%$ \\
\hline S20 & $0.24 \pm 0.05$ & $0.02 \pm 0$ & $0.80 \%$ \\
\hline
\end{tabular}

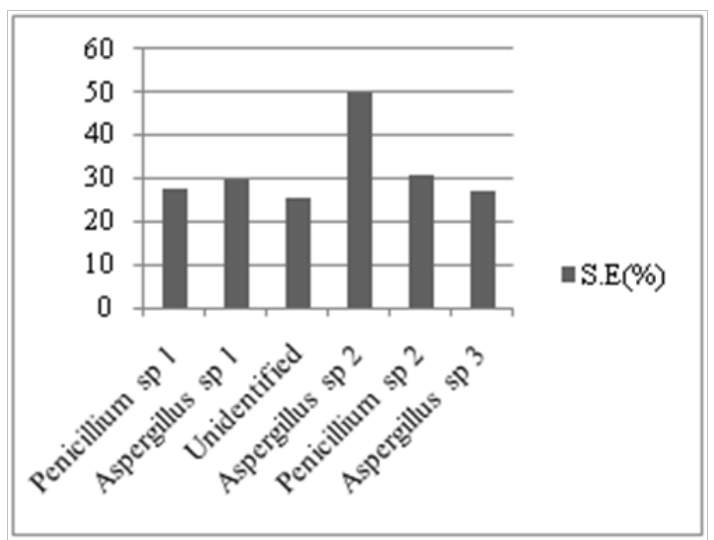

Figure I Solubilisation efficiency (\%) of fungi obtained from forest soil.

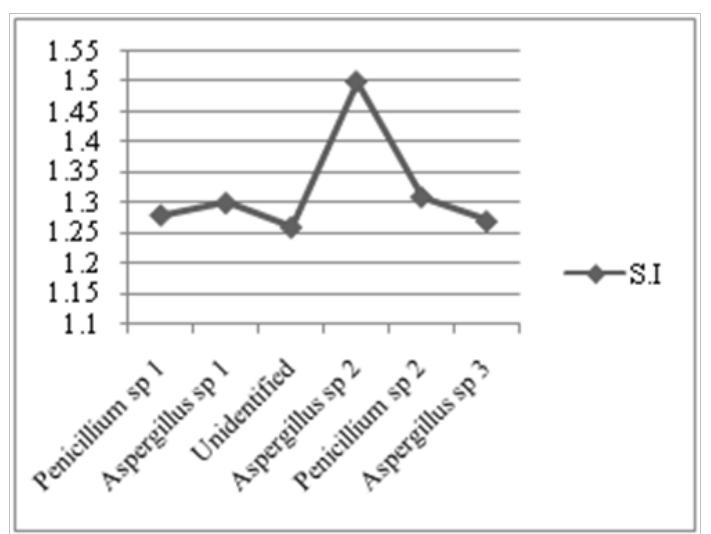

Figure 2 Solubilisation Index (SI) of phosphate solubilisation potential of Fungi obtained from forest soil.

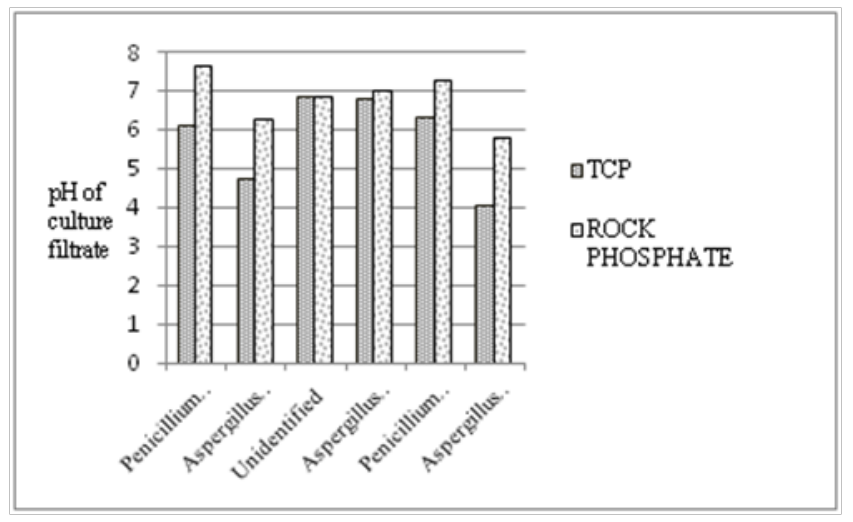

Figure 3 Profiling of $\mathrm{pH}$ of culture filtrate of fungi grown under TCP and rock phosphate supplementation.

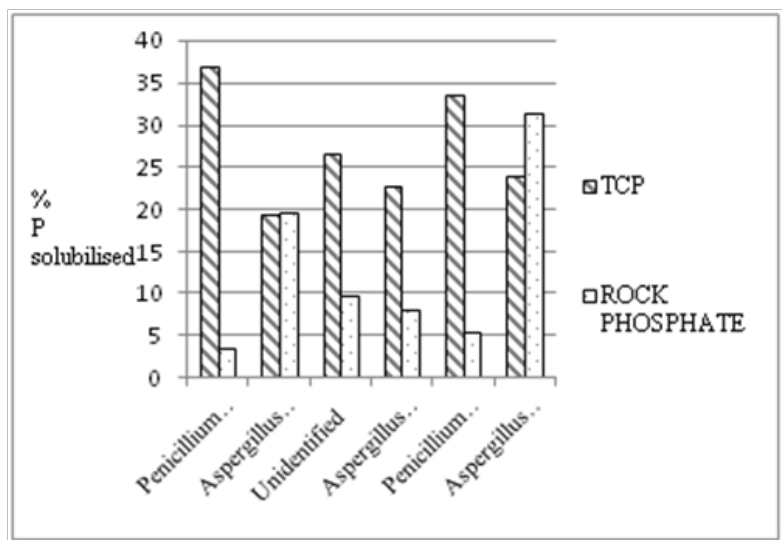

Figure 4 Solubilisation of phosphate (P content) by the fungi grown under TCP and Rock phosphate supplementation. 
The occurrence of mineral solubiliser especially phosphate solubilising fungi are evident from the present study. The evaluation of these fungi for phosphate solubilisation efficiency also confirms the exploitable potential of Aspergillus and Penicillium sp. found in this region. Further, small scale experiment under pot or field is required to achieve sharp evidence regarding the beneficial performance of these fungal strains.

\section{Acknowledgements}

The financial assistance obtained (in part) through Forest and Environment Department, Govt. of Odisha (State Plan Project) and INSPIRE programme, (No. DST/INSPIRE Fellowship/2013/506) DST, Govt. of India is gratefully acknowledged. The logistic support for Field visit and sampling of materials is also acknowledged to Division forest office of Khurdha district, Odisha.

\section{Conflict of interest}

The author declares no conflict of interest.

\section{References}

1. Das S, Lyla PS, Ajmal-Khan S. Bio geochemical processes in the continental slope of Bay of Bengal:I. Bacterial solubilization ofinorganic phosphate. Rev Biol Trop. 2007;55(1):1-9.

2. Banig AE, Aly EA, Khaled AA, et al. Isolation, characterization and application of bacterial population from agricultural soil at SohagProvince, Egypt. Malaysian J Microbiology. 2008;4(2):42-50.

3. Bardiya MC, Gaur AC. Rock phosphate dissolution by bacteria. Ind $J$ Microbiology. 1972;12:269-271.

4. Goldstein AH. Recent progress in understanding the molecular genetics and biochemistry of calcium phosphate solubilization by Gram negative bacteria. Biol Agric Horticulture. 1995;12:185-193.

5. Havlin J, Beaton J, Tisdale SL, et al. Soil fertility and fertilizers. Upper Saddle River, 499, New Jersey, USA: Prentice Hall; 1999.
6. Morales A, Alvear M, Valenzuela E, et al. Screening, evaluation and selection of phosphate-solubilising fungi as potential biofertilizer. $J$ Soil Sci Plant Nutrition. 2011;11:89-103.

7. Kundu BS, Nehra K, Yadav R. Biodiversity of phosphate solubilizing bacteria in rhizosphere of chickpea, mustard and wheat grown in different regions of Haryana. Ind J Microbiology. 2009;49(2):120-127.

8. Whitelaw MA. Growth promotion of plants inoculated with phosphate solubilizing fungi. Advances in Agronomy. 2000;69:99-151.

9. Bray RH, Kurtz LT. Determination of total, organic and available forms of phosphorus in soils. Soil science. 1945;104(1):242-249.

10. Mehrotra RS, Aneja KR. An introduction to mycology. New Delhi: Wiley eastern limited; 1990.

11. Mehrotra BS. The fungi-An introduction. 3rd ed. New Delhi: Today and Tomorrows Printers and publishers; 1992.

12. Gaur A, Rana J, Jalali B, et al. Role of VA mycorrhizae, phosphate solubilizing bacteria and their interactions on growth and up-take of nutrients by wheat crops. In: The National Conference on Mycorrhizae (1990: Hisar, India). Proceeding. Hisar, India: Trends in Mycorrhizal Research; 1990. p. 105-106.

13. Edi-Premono, Moawad MA,Vleck PLG. Effect of phosphate solubilizing Pseudmonasputida on the growth of maize and its survival in the rhizosphere. Indonasian J Crop Sci. 1996;11:13-23.

14. Jackson ML. Soil Chemical Analysis. Englowood cliff, New Jersey, USA: Prentice Hall Inc; 1958.

15. Pengnoo A, Hashidoko Y, OnthongJ, et al. Screening of phosphatesolubilizing microorganisms in rhizosphere and rhizoplane of adverse soiladapting plants in Southern Thailand. TROPICS. 2007;16(1):1-7.

16. Sahrawat KL, Jones MP, Diatta S. Response of upland rice to phosphorus in an Ultisol in the humic forest zone of West Africa. Fertilizer Research. 1995;41(1):11-17. 